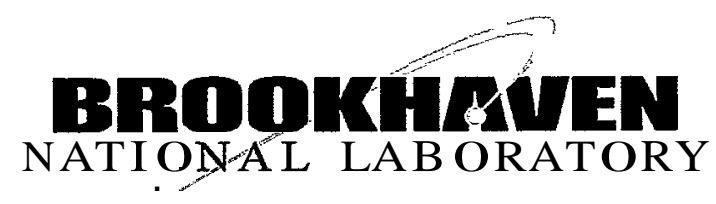

BNL-73492-2005-CP

\title{
Measurement and Optimization of Local Coupling from RHIC BPMData
}

\author{
R. Calaga, S. Abeytunge, M. Bai, W. Fischer, et al \\ Presented at the Particle Accelerator Conference(PAC'05) \\ Knoxville, Tennessee \\ May 16-20,2005
}

\author{
Collider-Accelerator Department \\ Brookhaven National Laboratory \\ P.O. Box 5000 \\ Upton, NY I1973-5000 \\ www.bnl.gov \\ Managed by \\ Brookhaven Science Associates, LLC \\ for the United States Department of Energy under \\ Contract No. DE-AC02-98CH10886
}

This is a preprint of a paper intended for publication in a journal or proceedings. Since changes may be made before publication, this preprint is made availablewith the understandingthat it will not be cited or reproducedwithout the permission of the author. 


\section{DISCLAIMER}

This report was prepared as an account of work sponsored by an agency of the United States Government. Neither the United States Government nor any agency thereof, nor any of their employees, nor any of their contractors, subcontractors, or their employees, makes any warranty, express or implied, or assumes any legal liability or responsibility for the accuracy, completeness, or any third party's use or the results of such use of any information, apparatus, product, or process disclosed, or represents that its use would not infringe privately owned rights. Reference herein to any specific commercial product, process, or service by trade name, trademark, manufacturer, or otherwise, does not necessarily constitute or imply its endorsement, recommendation, or favoring by the United States Government or any agency thereof or its contractors or subcontractors. The views and opinions of authors expressed herein do not necessarily state or reflect those of the United States Government or any agency thereof.

FOR UNCLASSIFIED, UNLIMITED STI PRODUCTS

Available electronically at:

OSTI:

\section{http://www.osti.gov/bridge}

Available for a processing fee to U.S. Department of Energy and its contractors, in paper from:

U.S. Department of Energy

Office of Scientific and Technical Information

P.O. Box 62

Oak Ridge, TN 37831

Phone: (865) 576-8401

Facsimile: (865) 576-5728

E-mail: reports@adonis.osti.gov

National Technical Information Service(NTIS):

Availablefor sale to the public from:

U.S. Department of Commerce

National Technical Information Service

5285 Port Royal Road

Springfield, VA 22131

Phone: (800) 553-6847

Facsimile: (703) 605-6900

Online ordering: http://www.ntis.gov/ordering.htm

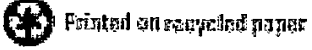




\title{
Measurement and optimization of local coupling from RHIC BPM data *
}

\author{
R. Calaga, S. Abeytunge, M. Bai, W. Fisches, BNL, NY 11973, USA \\ R. Tomás CELLS, Barcelona, Spain \\ A. Franchi GSI, Darmstadt, Germany
}

\section{Abstract}

Global coupling in RHIC is routinely corrected by using three skew quadrupole families to minimize the tune split $\left(\Delta Q_{m i n}\right)$. In this paper we propose to re-optimize transverse coupling by minimizing the resonance driving terms (RDT's) and the coupling matrix $\left(|\overline{\mathbf{C}}| / \gamma^{2}\right)$ in two steps: 1. Identify locations with coupling sources by inspection of the driving terms and the C-matrix around the ring and minimize the discontinuities and 2 . Find the best configurationof the three skew quadrupolefamilies to minimize both $\Delta Q_{\min }$ and RDTs $\left(f_{1001}\right)$. The measurements of $f_{1001}$ and $|\overline{\mathbf{C}}| / \gamma^{2}$ at injection and top energy to identify local coupling sources are presented.

\section{INTRODUCTIONAND MOTIVATION}

RHIC has the following relevant sources of transverse coupling:

- Skew quadrupolar errors in the interaction region(IR) magnets

- Tilts in the triplet quadrupoles

- Sextupolarfeed-down to skew quadrupolarfield at the chromaticity sextupoles and at all the dipoles

RHIC is equipped with three families of skew quadrupoles in the arcs to compensate global coupling. The coupling vectors of these families are represented in Fig. 1. In addition, RHIC is also equipped with two local skew correctors in each interaction region(IR). Global coupling is routinely corrected at RHIC by minimizing $\Delta Q_{\text {min }}$ using skew families either by a tune scan, a skew quadrupole modulation technique [1], or at injection using $\mathrm{N}$-turn maps [2]. Two families with a $90^{\circ}$ phase advance are enough to construct a unique coupling vector and minimize the closest tune approach. The RHIC coupling correction system consists of three families with a phase advance of $120^{\circ}$ between them. Therefore, there exists an infinite number of settings for three families that minimize the closest tune approach.

Assuming that the setting given by the vector $\left(f_{1}, f_{2}, f_{3}\right)$ minimizes the tune split. then any other setting of the form $\left(f_{1}+\Delta, f_{2}-\Delta, f_{3}+\Delta\right)$ with arbitrary $A$ is also a local minimum of the tune split. This feature can lead to situations in which the tune split is minimum (globally decoupled) but the machine is highly coupled locally. Fig. 2 shows an illustration by plotting the RDT, $\left|f_{1001}\right|$ around RHIC

* This work was performed under the auspices of the US Department of Energy

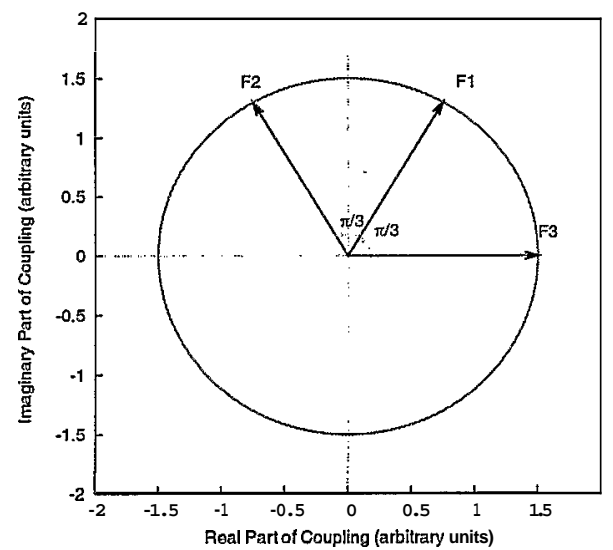

Figure 1: Coupling vectors of the three skew quadrupolar families of RHIC.

lattice (yellow ring) for different configuration of the three families, all yielding a $\Delta Q_{\min }$ of about 0.001 .

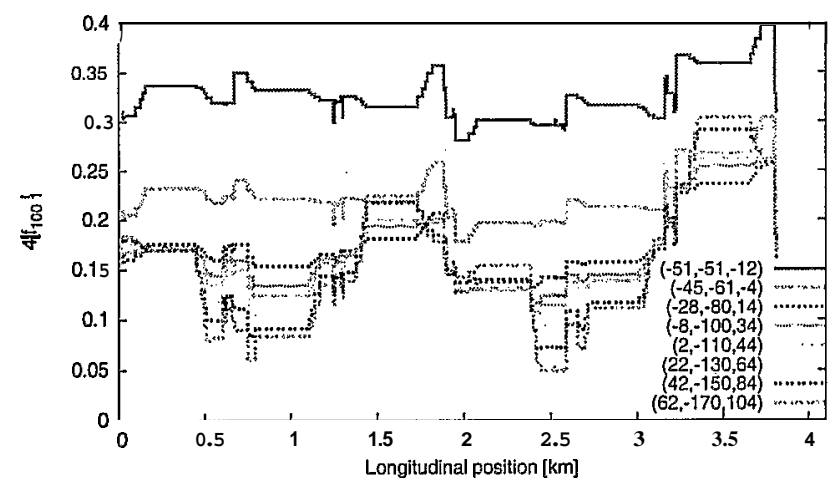

Figure 2: $f_{1001}$ from model for a set of different skew families configurations. All of them have a tune split close to 0.001 . The numbers in brackets represent the strength of the families in units of $10^{-5} \mathrm{~m}^{-1}$.

Although, different configurations all yield a minimum tune split, $\left|f_{1001}\right|$ varies significantly for each setting. The best setting should have the lowest values without large spikes. A good recipe is to minimize the average and the standard deviation at the same time. Situations as the top curve of the plot have an impact even in the machine optics and must be avoided. The measurement of the coupling RDTs and $\mathbf{C}$ matrix around the ring is the only way to ensure an optimum correction of coupling. 


\section{MEASUREMENT OF COUPLING RDT'S AND $|\overline{\mathrm{C}}| / \gamma^{2}$}

A variety of techniques to measure RDT's and the C matrix exist. Equivalence relations between the RDT's and C matrix were derived together with extensions to the existing techniques of measurement using BPM turn-by-turn data [3]. RHIC is uniquely equipped with an ac dipole to excite coherent betatron oscillations which are routinely used to measure RHIC optics $[4,5]$. An analytical formalism to measure RDT's in the presence of an ac dipole was proposed in [6] and the measurements of local and global sextupolar RDT's using BPM data generated from ac dipole excitation have been demonstrated at RHIC [7].

\section{Measurements at Injection Energy}

Beam experiments were performed during the 2005 polarized proton run to measure $f_{1001}$ and $|\overline{\mathbf{C}}| / \gamma^{2}$. Global coupling was initially corrected using the skew quadrupole families to minimize the tune split [1]. Coherent betatron oscillationsin both transverse planes were drivenusing two ac dipoles and BPM data were simultaneously recorded. The natural betatron tunes along with the ac dipole drive tunes and amplitudes are shown in Table 1.
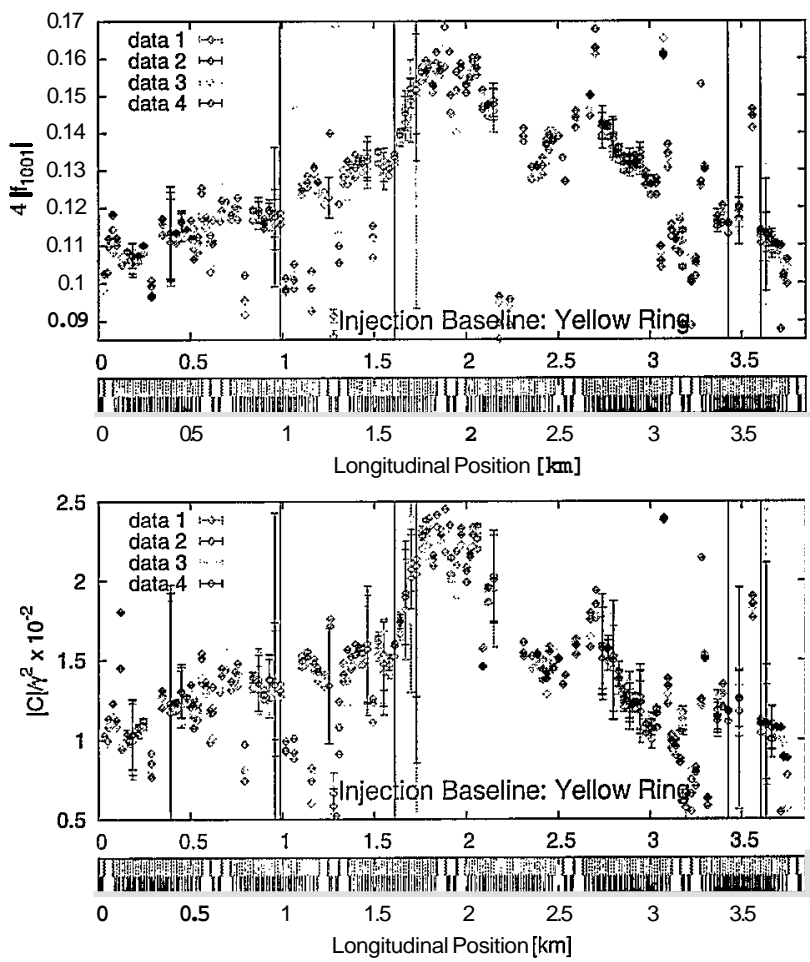

Figure 3: $4\left|f_{1001}\right|$ (top) and $|\overline{\mathbf{C}}| / \gamma^{2}$ (bottom) plotted as a function of longitudinal position along the yellow ring. A representation of the lattice (dipoles in black and quadrupoles in red) is shown in the bottom graph.

The data is initially processed to removefaulty BPMs according to criteria discussed in [8]. Approximately 10-15\% of the BPMs were found to be consistently faulty which
Table 1: Injection energy settings

\begin{tabular}{|l|c|c|c|c}
\hline \multirow{2}{*}{ Parameter } & \multicolumn{2}{|c|}{ Yellow } & \multicolumn{2}{c}{ Blue } \\
\cline { 2 - 5 } & $\mathrm{H}$ & $\mathrm{V}$ & $\mathrm{H}$ & $\mathrm{V}$ \\
\hline Tunes & 0.731 & 0.723 & 0.735 & 0.721 \\
Drive Tune & 0.74 & 0.719 & 0.745 & 0.712 \\
Drive Amp [mm] & 0.05 & 0.05 & 0.05 & 0.05 \\
\hline
\end{tabular}

were not used in this analysis. Fig. 3 shows four measurements of $f_{1001}$ and $|\overline{\mathbf{C}}| / \gamma^{2}$ as a function of longitudinal position in the yellow ring.
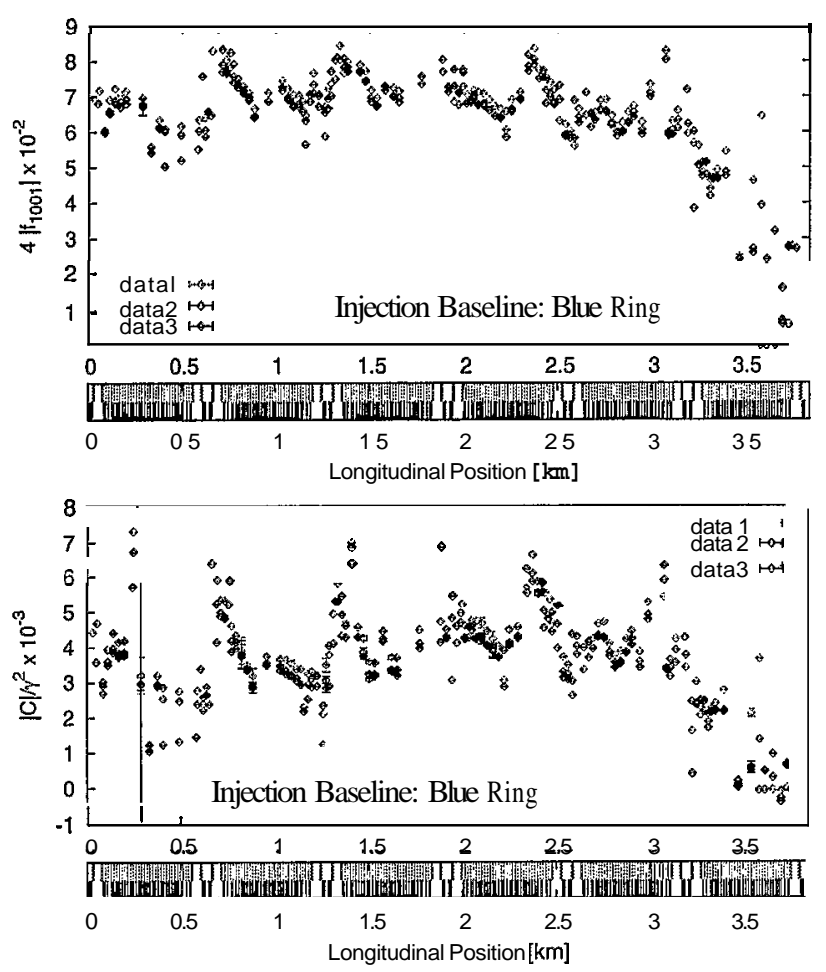

Figure 4: $4\left|f_{1001}\right|$ (top) and $|\overrightarrow{\mathbf{C}}| / \gamma^{2}$ (bottom) plotted as a function of longitudinal position along the blue ring.

Although globally decoupled, the $f_{1001}$ and $|\overline{\mathbf{C}}| / \gamma^{2}$ in the yellow ring (Fig. 3) shows significant variations in the ring indicating uncorrected local coupling sources. $f_{1001}$ and $|\overline{\mathbf{C}}| / \gamma^{2}$ in the blue ring (Fig. 4) looks relatively flat and also globally well decoupled. The goal of future experiments would be to precisely identify and measure these local sources and use local IR correctors to compensate them. The procedure will involve scanning local skew correctors in each IR and minimize the local jumps in $f_{1001}$. The residual coupling will be further compensated with global skew families that yields the minimum $f_{1001}$ for the minimum achievable $\Delta Q_{\min }$.

A systematic scan of a local corrector in IR8 (yo9sq3) was performed as an initial experiment and $f_{1001}$ and $|\overline{\boldsymbol{C}}| / \gamma^{2}$ were measured. Both positive and negative deviations from its nominal value increases the global coupling which is evident from the increase in $f_{1001}$. Therefore, an effective local correction would also entail a simultaneous 
global family correction for each local scan value.

\section{Measurements ut Top Energy}

RHIC operates close to the difference coupling resonance which requires effective decoupling at top energy. A similar experiment as at injection was performed at top energy for the blue ring to measure $f_{1001}$ and $|\overline{\mathbf{C}}| / \gamma^{2}$. Global coupling was initially compensated like at injection and the skew families were set at nominal operation values. The settings for the tunes and amplitudes for top energy in the blue ring are shown in Table 2.

\begin{tabular}{|l|c|c|c|c|}
\hline \multirow{2}{*}{ Parameter } & \multicolumn{2}{|c|}{ Blue } & \multicolumn{2}{c|}{ Yellow } \\
\cline { 2 - 5 } & $\mathrm{H}$ & $\mathrm{V}$ & $\mathrm{H}$ & $\mathrm{V}$ \\
\hline Tune & 0.684 & 0.694 & 0.697 & 0.685 \\
Drive Tune & 0.675 & 0.703 & 0.705 & 0.675 \\
Drive Amp [mm] & 0.2 & 0.2 & 0.3 & 0.3 \\
\hline
\end{tabular}

The data was processed to remove faulty BPMs similar to the injection data. However, the BPMs between IR4 $\operatorname{IR6}(3.5-3.85 \mathrm{~km})$ in blue ring yield a zero $f_{1001}$ which is being investigated. Fig. 5 shows a measurement of $f_{1001}$ at top energy for the blue ring. A large discontinuity in $f_{1001}$ is observed at IR12 $(2 \mathrm{~km})$ and smaller ones at IR8 $(0.5$ $\mathrm{km})$ and IR4 (3 km) which indicate local skew sources.
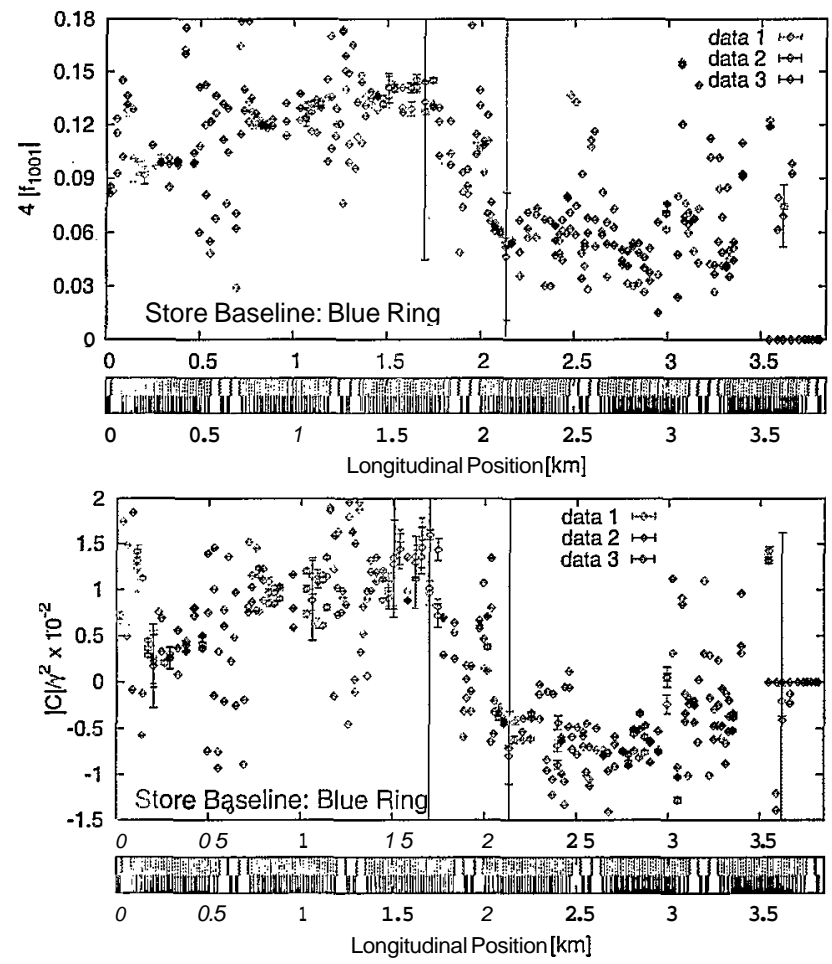

Figure 5: 4. $\left|f_{1001}\right|$ (top) and $|\overline{\mathbf{C}}| / \tilde{\gamma}^{2}$ (bottom) plotted as a function of longitudinal position along the blue ring.

The yellow ring exhibits large discontinuities at IR8 (0.5 $\mathrm{km})$ and IR2 $(2.5 \mathrm{~km})$ as shown Fig. 6. A similar correction scheme proposed for injection using IR corrector scan will be used at top energy to minimize the discontinuities in $f_{1001}$.
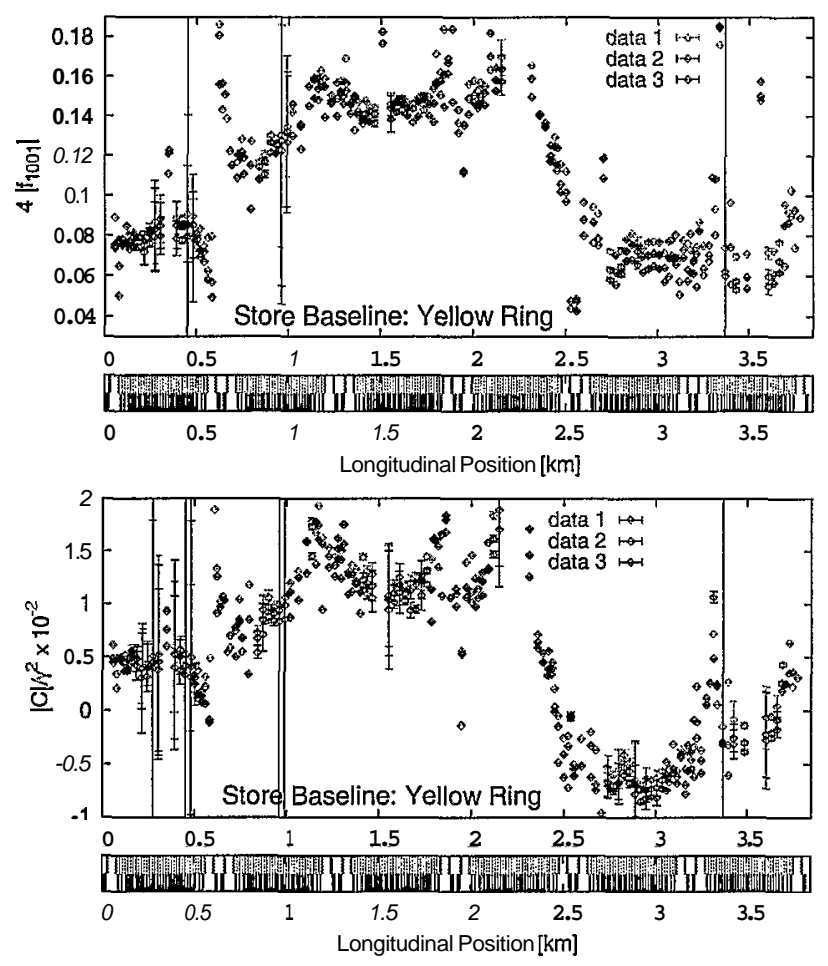

Figure 6: $4\left|f_{1001}\right|$ (top) and $|\overline{\mathrm{C}}| / \gamma^{2}$ (bottom) plotted as a function of longitudinal position along the yellow ring at top energy.

\section{ACKNOWLEDGEMENTS}

We would like to thank the operations group for their help during data acquisition.

\section{REFERENCES}

[1] Y. Luo et al., "Measurement of global betatron coupling with skew quadrupole modulation", Phys. Rev. ST Accel. Beams 8,014001 (2005).

[2] W. Fischer, "Robust Linear Coupling Correction with Nturn Maps", Phys. Rev. ST. Accel. Beams 6,062801, BNL71379-2003-JA, BNL C-A/A.P/99 (2003).

[3] R. Calaga, R. Tomás, and A. Franchi, "Betatron coupling: Merging Hamiltonian and matrix approaches", Phys. Rev. ST Accel. Beams 8,034001 (2005)

[4] M. Bai et al., "Measuring Beta Function and Phase Advance in RHIC with an ac dipole", The proceedings of the 2003 Particle Accelerator Conference, Portland (May 2003).

[5] R. Calaga et al., "RHIC Optics Measurement with Different Working Points", The proceedings of the 2004 Particle Accelerator Conference, Lucerne (May 2004).

[6] R. Tomás, "Normal form of particle motion under the influence of an ac dipole", Phys. Rev. ST Accel. Beams 5, 054001 (2002). 